\title{
Aspectos de la Reforma en Aragón a finales del reinado del Emperador. El proceso del rector Miguel Monterde
}

\author{
Michel Boeglin \\ Université Paul Valéry - Montpellier 3
}

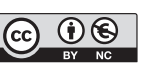

Recibido: diciembre de 2011

Aceptado: julio de 2012

\section{Resumen}

El presbítero Miguel Monterde (1510?-1571) fue racionero de la seo de Zaragoza y rector de Villanueva de la Huerva. Antiguo estudiante de Alcalá, tuvo allí como maestro al doctor Juan Gil, comúnmente conocido como «Doctor Egidio», que, posteriormente, sería uno de los principales difusores de la sensibilidad reformada en Castilla y Aragón. En el año 1558, la Inquisición procesó a Monterde por sus estrechos contactos con su antiguo maestro, así como con otro discípulo de éste, Juan Pérez de Pineda. La relación del proceso de Miguel Monterde, inédita, aporta una información relevante sobre la actuación de Egidio después de su condena de 1552 y el sistema de captación de fondos y de difusión de obras protestantes en castellano publicadas en Ginebra.

Palabras clave: luteranismo; protestantismo; libros; Aragón; Sevilla; París; Miguel Monterde; Juan Gil; Doctor Egidio; Juan Pérez de Pineda; Constantino de la Fuente, Constantino Ponce de la Fuente.

Resum. Aspectes de la Reforma a l'Aragó a finals del regnat de l'Emperador. El procés del rector Miguel Monterde

El prevere Miguel Monterde (1510?-1571) va ser racioner de la seu de Saragossa i rector de Villanueva de la Huerva. Antic estudiant d'Alcalà, va tenir allà com a mestre el doctor Juan Gil, comunament conegut per «Doctor Egidio», que, posteriorment, seria un dels difusors principals de la sensibilitat reformada a Castella i Aragó. L’any 1558, la Inquisició va processar Monterde pels estrets contactes que mantenia amb el seu antic mestre i també amb un altre deixeble d'aquest, Juan Pérez de Pineda. La relació del procés de Miguel Monterde, inèdita, aporta una informació rellevant sobre l'actuació d'Egidio després de la seva condemna de 1552 i el sistema de captació de fons i de distribució d'obres protestants en castellà publicades a Ginebra.

Paraules clau: luteranisme; protestantisme; llibres; Aragó; Sevilla; París; Miguel Monterde; Juan Gil; Doctor Egidio; Juan Pérez de Pineda; Constantino de la Fuente, Constantino Ponce de la Fuente.

Abstract. Aspects of Reformation in Aragon at the end of Charles V's reign. The trial of the rector Miguel Monterde

The cleric Miguel Monterde (1510?-1571) was prebendary of the Cathedral of Zaragoza and rector of a rectory in Villanueva de la Huerva. He was a former student of Alcalá de Henares where his teacher was Dr. Juan Gil, commonly known as «Doctor Egidio». Later on, Doctor 
Egidio would become one of the main disseminators of the reformed sensibility in Castile and Aragón. In 1558, the Spanish Inquisition prosecuted Monterde for his relationship with his former teacher and another disciple of Doctor Egidio, Juan Pérez de Pineda. The unpublished abstract of the process provides us with relevant information about the activity of Doctor Egidio after he was condemned in 1552 and about the system of fundraising and distribution of Protestant works published in spanish in XVI ${ }^{\text {th }}$ century Geneva.

Keywords: Lutheranism; Protestantism; books; Aragon; Seville; Paris; Miguel Monterde; Juan Gil; Doctor Egidio; Juan Pérez de Pineda; Constantino de la Fuente, Constantino Ponce de la Fuente.

Menos conocido que los grupos sevillanos y vallisoletanos desarraigados por la Inquisición entre 1557 y 1560, el círculo luterano de Aragón fue objeto de una mayor atención a partir de los estudios pioneros de A. Gordon Kinder en los años 1980 y objeto de una nueva valoración (Kinder, 1986b) ${ }^{1}$. La proximidad de la frontera pirenaica, los numerosos intercambios y los fuertes vínculos con Francia facilitaron la difusión, en determinados cenáculos aragoneses, de doctrinas reformadas. En Zaragoza, se tiene constancia de unas quince sentencias de luteranismo pronunciadas contra naturales de Aragón entre 1560 y 1563, poco después de que se descubrieran los círculos de Valladolid y Sevilla.

Entre las causas despachadas por el tribunal zaragozano, descuella la del rector Miguel Monterde, personalidad eclesiástica destacada, un humanista erudito abierto a los grandes planteamientos religiosos de su tiempo. Cercano a otro aragonés, Juan Gil, comúnmente conocido como «Doctor Egidio», canónigo magistral de Sevilla, el rector Monterde estuvo en relación con varios súbditos de la Corona exiliados que se habían adherido a la Reforma. Su caso ilustra el destino, en los últimos años, del reinado de Carlos $\mathrm{V}$ de aquellos erasmistas e irenistas, quienes habían defendido, hasta finales de la década de 1540, un acercamiento de Roma con el partido de la Reforma para propiciar una concordia en los asuntos religiosos.

Clérigo presbítero, Miguel Monterde era, a mediados del siglo XVI, racionero de la seo de Zaragoza y regentaba una rectoría en Villanueva de la Huerva, a unas leguas de la capital aragonesa, donde era comúnmente considerado y apreciado por su labor. Hombre de gran sabiduría y erudición, era un humanista versado en teología, sabio en idiomas extranjeros, como lo recordaba el bibliógrafo aragonés Felix Latassa (Gómez Uriel, 2001: 348). También recopiló crónicas históricas y poseía notables conocimientos en las virtudes farmacéuticas de las plantas, según su amigo, el médico humanista doctor Lucena (Andrés de Uztárroz, 1680: 481-482)².

1. Para Valencia, ver Almenara y Ardit, 1998. Ver también Thomas, 2001, p. 40-41 y 247-249.

2. Carta de Juan Páez de Castro al Dr. Lucena del 1 de septiembre de 1549. El rector Monterde tradujo, entre otras obras, parte de la Crónica de Ramón Montaner, del provenzal al castellano y, del italiano, la Relación de Micer Bernardo Navajero, baylio en la corte del Gran Turco en Estambul. 
Mantuvo correspondencia con los cronistas Jerónimo Zurita y Bartolomé Llorente, con el jurisconsulto Batista de Lanuza, justicia mayor de Aragón y diversas personalidades eclesiásticas de su tiempo (Gómez Uriel, 2001: 348).

Cursó en Alcalá de Henares, donde había tenido por maestro a un conterráneo suyo, el doctor Juan Gil, que ejercería una profunda influencia en él, a cuyas clases de Artes y Filosofía había acudido, cuando éste enseñó en San Ildefonso, entre 1525 y $1527^{3}$. Podemos suponer, por tanto, que nació en torno a los años 1505 y 1510. Los títulos sacados en la prestigiosa universidad complutense y su erudición le destinaban a una brillante carrera que le condujo a viajar por España y, luego, a Roma, antes de acompañar al emperador y su séquito a Flandes y Alemania, pasando por Brujas, Bruselas y Worms, en 1545.

También se había hallado en el segundo coloquio de Ratisbona de 1546, entre los letrados y los delegados españoles presentes en las reuniones destinadas a hallar, sin éxito, una concordia entre católicos y reformados ${ }^{4}$. A continuación, volvió a Roma, donde pudo coincidir con su amigo aragonés Juan Morillo, que había integrado el grupo de los spirituali italianos. Su incansable curiosidad, sus lecturas, sus viajes a Flandes y Alemania, así como su presencia en las dietas del Imperio, en que pudo familiarizarse con la postura religiosa de los protestantes, habían despertado la inquietud de esta personalidad preocupada por el devenir de la cristiandad y, sin lugar a dudas, afín a las posturas del partido erasmista y de los cardenales más abiertos al diálogo con los protestantes. Animado por un profundo espíritu crítico, nutriendo su reflexión de Erasmo y probablemente de Lutero y otros reformadores, cuyas posturas teológicas sobre determinados puntos de doctrina conocía sobradamente, había lamentado las posiciones del papado sobre ciertos puntos de discordia con los reformados.

Aquellas afirmaciones provocaron el inicio de su causa en la Inquisición de Zaragoza. En 1546, a su vuelta de Ratisbona, había sido presentada una primera denuncia en Barcelona contra el rector Monterde por un cierto licenciado Carlos, capellán del emperador, por ciertas palabras a favor de los protestantes. El eclesiástico aragonés había afirmado, ante un grupo de personas, entre las que se hallaban su amigo don Alonso de Ariago, don Alonso Manrique de Mendoza y el testigo que le denunció, que la postura de Lutero era justificada en determinados puntos de discordia con la Iglesia romana (Kinder, 1986b: 183, 189-190). El caso se archivó en aquel momento. En 1557, cuando se descubrieron los denominados «círculos luteranos» de Sevilla y Valladolid y que cundió en Castilla y en Aragón el temor de ver varias ciudades del reino afectadas por la difusión del protestantismo, la Inquisición de Zaragoza volvió a abrir el expediente.

En 1558, se inició el proceso recogiendo el testimonio inicial, según el cual, en Ratisbona,

[...] hablando de las cosas de los luteranos oyó [el testigo] decir al dicho rector que los luteranos tenían razón de no obedecer al Papa en muchas cosas porque el voto

3. AHN, Inq., leg. 3570, caja 1, Méritos del proceso del rector Monterde, f. 2r.-v.

4. Ibídem, f. 2r. Sobre el coloquio de Ratisbona de 1546, véase Lecler, 1955, vol. I, p. 235-238; Pollet, 1990, p. 201-205. 
de celibato de clérigos y otros de la Iglesia, más eran redes para llevar los hombres al infierno que no leyes para el cielo y que, diciéndole [el testigo] que para qué se había ordenado si no pensaba guardar los votos, respondió que por vivir a su placer de los bienes de la Iglesia sin trabajar y que el dicho rector defendía el comunicar in [sic] utraque specie, conforme a la opinión de los luteranos ${ }^{5}$.

Detenido Monterde, reconoció, durante las audiencias con los inquisidores, que, de camino para Ratisbona, había tenido una discusión sobre el matrimonio de los clérigos con un cierto Mendoza, criado de don Alonso de Aragón. Fundándose en las epístolas de San Pablo a Timoteo, justificó la postura de Lutero y rebatió los ataques del criado de Alonso Manrique de Mendoza, que defendía el celibato y se escandalizaba de la postura de los protestantes, espetándole «de eso sabéis vos muy poco, porque si atendiesedes a los inconvenientes que de ello se siguen, no diríades eso pero como vos andáis de puta en puta, no lo echáis de $v^{6}{ }^{6} »$. En sus defensas, el rector se justificó ante los jueces explicando que la cuestión del voto de celibato, tal y como estaba interpretada por la Iglesia católica, constituía, a sus ojos, uno de los principales puntos de discordia entre católicos y protestantes.

La segunda gran diferencia entre cristianos, según detalló a los inquisidores en las audiencias, tocaba a la confesión auricular, terreno en el que Roma y los reformados hubiesen debido hallar un acuerdo ${ }^{7}$. Por fin, el tercer gran escollo en las discusiones entre ambos partidos era la cuestión de la comunión. Consideraba el rector que comulgar sub utraque specie, bajo las dos especies, estaba más acorde a las Sagradas Escrituras. En este punto, afirmó fundarse en la exposición de Erasmo sobre el salmo Quam dilecta tabernacula tua, que había titulado De concordia eclesiástica ${ }^{8}$.

Como buen humanista cristiano, sensible a las posiciones de los protestantes, era partidario de un cristianismo auténtico, fundado en los Evangelios y respetuoso con los puntos de vista ajenos, en la misma perspectiva que el pensador de Rotterdam. Se mostraba crítico con los clérigos y defendía que la Iglesia refrenase y censurase sus abusos para facilitar una concordia con los protestantes. En particular, aclaraba, Roma debía acabar con la simonía de los eclesiásticos y «aplacar sus contiendas movidas por intereses» ${ }^{9}$. De los canónigos, afirmaba con talante irónico, que sólo les quedaba de religión el ir al refectorio, «que todo lo demás era cobrar dinero» ${ }^{10}$. Y la cuestión de la simonía también aparecía en otra declaración suya, según la cual uno de los grandes escándalos que Roma había

5. AHN, Inq., leg. 3570, caja 1, Méritos..., f. 2r.

6. Ibídem, f. 3r.

7. Lutero, al inicio, había rechazado cualquier valor sacramental a la confesión, aunque posteriormente había ido mudando de opinión. Reconoció su valor para los fieles y atendió a las justificaciones de Melancton, cuando Calvino, al contrario, no quería ver en la confesión hecha ante un ministro de Dios sino un instrumento de la tiranía papal sobre las conciencias.

8. AHN, Inq., leg. 3570, caja 1, Méritos..., f. 2v. Se trata de la obra de Erasmo, De sarcienda ecclesiae concordia, París, 1533.

9. Ibídem, f. 2v.

10. Ibídem. 
remediar era el tráfico de indulgencias, «pues muchos profanos se guardan de hacer buenas obras porque se confiaban en ellas» ${ }^{11}$. Su talante humanista lo revelaban también sus declaraciones en las que decía no poder sufrir a los predicadores «que predicaban en sus sermones a Aristóteles», refiriéndose a los escolásticos, y decantándose por aquellos que buscaban nuevas formas para difundir la palabra de Dios entre los fieles y se mostraban más atentos a la elocuencia, en conformidad con lo propugnado por Erasmo en su Eclesiastes ${ }^{12}$.

$\mathrm{Su}$ sensibilidad se inscribía aparentemente dentro de las grandes corrientes erasmianas españolas, pero su conocimiento y su defensa de las posiciones de los reformados en varios puntos de doctrina fueron despertando las suspicacias de los jueces. El afirmar que los luteranos tenían razón de no obedecer al papa en muchas cosas podía delatar otro tipo de actitud ${ }^{13}$. De hecho, ante los inquisidores, se había ceñido a una línea de defensa centrada en torno a Erasmo, en cuestiones como la comunión, para deshacerse de sospechas de simpatías por las doctrinas reformadas. Pero evitó prudentemente temas más candentes en aquellos años, en que aún no se había clausurado el Concilio de Trento, como la justificación por la fe o los méritos de Cristo, también tratados por Erasmo en su De sarcienda ecclesiae concordia, de 1533, pero cuyos planteamientos, particularmente en España, resultaban arriesgados. Frente a ciertas acusaciones, apoyarse en Erasmo era una cómoda forma de desviar graves sospechas de herejía y resultaba preferible afirmar seguir posturas defendidas por el humanista holandés, que gozaba del aura de la ortodoxia, a pesar del ocaso del partido erasmista en la corte imperial desde la década de 1540 (Seidel Menchi, 1996; Martínez Millán, 2004).

$* * *$

En las sucesivas audiencias con los inquisidores, reconoció que había hablado de varios puntos del dogma, «en nombre de los luteranos, relatando lo que había entendido de sus opiniones, mostrando alguna afición a opiniones semejantes [...] deseando legítimamente [que] la Iglesia diese orden en ello». Cercano a las posiciones de los irenistas castellanos, que defendían, aún en la década de 1540, una progresión del dogma para llegar a un acuerdo con los protestantes, compartía los planteamientos del partido católico reformado de los spirituali. Sus relaciones con varios encausados por herejía en 1557 o con personas ya condenadas entonces, como los aragoneses Juan Morillo (o Murillo), Francisco Mudarra (o Mudurra), Mateo Pascual o el Doctor Egidio, o con el castellano Agustín Cazalla, delataban una adscripción a planteamientos religiosos afines al protestantismo y a una postura de apertura y de diálogo que, desde 1545, había sido abandonada por la curia romana. Consciente de ello y para defenderse, afirmó, ante los jueces, que posiblemente algunas palabras suyas o confidencias hechas a ciertas personas procesadas habían podido motivar su arresto en la Aljafería ${ }^{14}$.

11. Ibídem.

12. Ibídem.

13. Ibídem, f. 2r.

14. Ibídem. 
No obstante, en el momento de las primeras audiencias, ya sabía Miguel Monterde que el potencial y principal acusador que habría de ponerle en aprietos era, si se decidía a colaborar con los jueces, Julián Hernández, comúnmente conocido como Julianillo, entonces detenido en la Inquisición de Sevilla por haber distribuido obras de propaganda protestante. Una carta de los inquisidores de Zaragoza de finales de septiembre de 1558 dejaba claro que el rector, entonces detenido, «está temeroso no testifique contra él aquel Julián» ${ }^{15}$. Y, efectivamente, las declaraciones efectuadas por Julián Hernández resultaban particularmente comprometedoras. A diferencia de la imagen legada por el Reginaldo Montes, luego repetida en los martirologios protestantes, Julianillo no logró resistir a los apremios ni a las torturas de los inquisidores y acabó proporcionando informaciones sobre diferentes personas con las que se había encontrado, dentro y fuera de España, y detalló ciertas confidencias hechas por el exiliado reformado Juan Pérez de Pineda (Castrillo Benito, 1991: 387-393; Longhurst, 1960; López Muñoz, 2011: I, 109-114).

Julián Hernández nació en 1531 o 1532 en Valverde, población de Castilla (Longhurst, 1960; Kinder, 1986b: 198). En torno a 1551, había abandonado España y, tras varios viajes a Flandes, donde pudo coincidir con el exiliado Juan Pérez de Pineda, se había asentado en Estrasburgo, donde se había casado, según afirmó a Miguel Monterde ${ }^{16}$. Conociendo el proselitismo de Julianillo y la determinación de su carácter, Juan Pérez de Pineda le había elegido para realizar ciertos trámites en relación con sus proyectos de edición y distribución en la Península de obras reformadas en castellano. En, por lo menos, dos ocasiones mandó a Julián Hernández a España, la primera, probablemente en 1555 y, la segunda, en la primavera de 1557, que acabó con su arresto en Sevilla. En una de sus primeras cartas dirigidas a Miguel Monterde, en 1555, Juan Pérez le anunciaba que «un mensajero va a ver la tierra para conocer qué disposición hay y en qué estado están las cosas de los píos afligidos por el amor de Dios» ${ }^{17}$. Se trataba, para Julianillo, en este primer viaje, de sondear los ánimos, pero también de recaudar fondos para costear la edición del Nuevo Testamento en romance y otras obras reformadas que proyectaba llevar a imprenta Juan Pérez de Pineda ${ }^{18}$.

La primera vez que «aquel hombrecito pequeño desarrapado» se presentó en casa de Monterde, según la descripción que éste dio, era para aclarar el estado de un envío de unos 400 ducados a Juan Pérez, que un cierto Juan de Santángel tenía encomendado al rector. Natural de Calatayud, Santángel era estudiante en París y, cuando volvió a Aragón, fue a ver a Monterde con unas cartas de recomenda-

15. AHN, Inq., libro 961, f. 532v.-533r. (28.9.1558): «[...] y así lo ha dicho en el examen general que teme no lo hayan prendido porque este hombrecillo [Julianillo] no haya dicho en Castilla entre sus amigos que este Monterde era uno de ellos porque [siendo] rector, fue amigo de Morillo y de Egidio y discípulo suyo y eso de Cazalla y Mudurra que fue condenado en Roma en ausencia y de otro Mateo Pascual que también fue penitenciado o reconciliado [en Toledo]».

16. AHN, Inq., leg. 3570 , f. 4 r.

17. Ibídem.

18. Sobre dichas obras publicadas entre 1556 y 1557, ver Droz, 1960, p. 119-132; García Pinilla, 2012, p. 45-46. Ver también más bajo p. 151. 
ción que le habían escrito los «sobrinos del prior del Pilar», asentados en la capital francesa y de cuyo mantenimiento se ocupaba el rector. A la hora de retornar a Francia, Juan de Santángel enfermó durante el viaje y murió poco después, probablemente a principios de 1555. Al fallecer, dejó una nota pidiéndole al rector que enviara la suma de 400 ducados a Juan Pérez de Pineda, para que éste se encargara de entregarlos a un «hijo bastardo que dejaba en Francia» y que, en caso de no encontrarse o que hubiese fallecido, los empleara «al edificio del templo de Nuestro Señor». La expresión en cifra designaba la propagación de la confesión reformada en España y, más concretamente, los proyectos de publicación de obras de propaganda protestante en castellano llevados a cabo por el que hubo de ser su anfitrión en París, Juan Pérez de Pineda ${ }^{19}$.

Julianillo explicó a los jueces que Pérez de Pineda había recibido el recado de Monterde, quien le señalaba que la suma pronto le sería enviada por medio de unos mercaderes, pero sin indicar el origen del donativo. Puesto que dudaba de que se tratara de una iniciativa del rector, al que no conocía en persona, y ante la demora en recibir esta suma considerable destinada a financiar los costes de las ediciones, Juan Pérez de Pineda le había encargado a su enviado que fuera cerciorándose de su destino o que la recaudara ${ }^{20}$. Tras su estancia en Zaragoza, Hernández tenía que ir a diversos lugares de Castilla y a Sevilla para entregar cartas a amigos de Juan Pérez e invitarlos a participar en la financiación de dicha empresa editorial ${ }^{21}$.

Cauto ante los jueces, el rector afirmó haberse percatado de la naturaleza verdadera de dichas obras sólo al oír el edicto de prohibición del Santo Oficio referente a los libros de Juan Pérez de Pineda y, asimismo, afirmó conocerlo únicamente por haberse carteado con él entre mayo de 1555 y agosto de 1556, el tiempo que duraron los trámites para entregar las sumas dejadas por Santángel ${ }^{22}$. Sin embargo, aquello era cierto sólo en parte, dado que ya había estado en relación con Pérez de Pineda anteriormente y le había mandado dinero para el mantenimiento de los sobrinos del prior del Pilar que tenía a su cargo.

Ahora bien, las relaciones que mantuvieron Juan Pérez de Pineda y Miguel Monterde durante el año que duró su correspondencia eran lo suficientemente estrechas como para despertar las sospechas de los jueces cuando se descubrió, en el secuestro de los bienes del rector, el cartapacio donde se hallaban cartas mandadas desde París, firmadas «Pierius» o «Pierio». A partir de septiembre de 1558, cuando los inquisidores fueron identificando a Juan Pérez, del que sólo sabían que era estudiante en París, con el fugitivo de Sevilla que había salido

19. AHN, Inq., leg. 3570, f. 3v. En sus defensas, Monterde afirmó que ni Santángel ni Julián Hernández le aclararon qué era «aquella casa de Dios», que el segundo únicamente le había contestado que el dinero enviado se destinaría a ciertas limosnas para estudiantes pobres en París, sin hablarle de los proyectos editoriales de Pérez de Pineda, que afirmó ignorar hasta el día en que recibió ejemplares salidos de la prensa de Ginebra. Ibídem, f. 5r.

20. Ibídem., f. 5r.

21. Ver la relación de la sentencia de Gaspar Ortiz publicada por Huerga, 1990, p. 4107-4144, y López Muñoz, 2011, vol. II, p. 349-355.

22. Ibídem, f. $4 \mathrm{v}$. 
cuando se había procesado por primera vez a Egidio, en 1549, la causa de Monterde fue tomando otro cariz ${ }^{23}$.

Natural de Montilla, en la diócesis de Córdoba, aquel discípulo del doctor Juan Gil pudo seguir sus clases en Alcalá, aunque no tenemos constancia de que se hubiese graduado allíi ${ }^{4}$. Había huido de Sevilla en compañía de otros dos seguidores del predicador y canónigo magistral, Luis Hernández, alias «Del Castillo», y Diego de la Cruz, cuando había sido encarcelado el canónigo magistral por los inquisidores. Los tres formaban parte, sin lugar a dudas, de la «pequeña iglesia» de Sevilla, el grupo nicodemita en que se propugnaba una vuelta al espíritu del Evangelio y que, bajo el magisterio del Doctor Egidio, defendía una sensibilidad religiosa que se alejaba de la doctrina romana y que, tanto en la doctrina de los sacramentos como en la concepción de los méritos de Cristo y el carácter no retributivo de las obras, se fundaba en interpretaciones de Juan de Valdés, de Lutero y Melanchthon ${ }^{25}$. Habían enseñado, por lo menos dos de ellos, en la Casa de los Niños de la Doctrina, en Sevilla, donde ejercieron varios discípulos de Egidio y Constantino de la Fuente, posteriormente condenados por luteranismo.

De Sevilla, Juan Pérez fue a París, con sus dos compañeros. En la capital francesa, se asentó junto con sus dos amigos en casa del aragonés Juan Morillo, otro amigo de Monterde, quien profesaba ya entonces la fe protestante y organizaba en su casa debates y ceremonias siguiendo el rito alemán e inglés ${ }^{26}$. Natural de Biel, en Valdonsilla, Morillo había manifestado un precoz interés por la Reforma. Había acudido a Trento en el séquito del obispo de Clermont, Guillaume du Prat, y, después de la primera suspensión del Concilio, había pasado al servicio del cardenal Reginaldo Pole. Integró, así, el círculo compuesto por Giovani Morone, Pietro Carnesecchi, Luigi Priuli, Marco Antonio Flaminio y otros spirituali del partido católico reformado italiano. También mantuvo discusiones en Roma y luego una correspondencia con el arzobispo Bartolomé Carranza de Miranda ${ }^{27}$. En este grupo, que abogaba por una conciliación con los protestantes y una reforma de la

23. AHN, Inq., libro 961, f. 532v.-533r. (28.9.1558): «El Juan Pérez que dice V Sas. que debe ser estudiante en París tengo por cierto que éste es Juan Pérez cuyas obras se han reprobado y a quien un maestro Juan de Santángel, natural de este reino, que es difunto, envió los dineros para imprimirlos por medio de este rector. Y este Juan Pérez, si no me engaño por los rastros que tengo y a lo que me quiero acordar del tiempo de Sevilla, se ausentó cuando prendieron al doctor Egidio y creo que si se advierte a los inquisidores de Sevilla habrá alguna información contra él. Y un testigo que aquí hemos examinado, que ha residido en París [Jaime Sánchez?], dice que el dicho Juan Pérez era sevillano y que oyó decir a algunas personas que se había ido huyendo de Sevilla cuando prendieron a Egidio, y a otros que lo habían desterrado por la Inquisición, y a otros que el dicho Egidio lo había enviado por el doctor Morillo cuando lo eligieron por obispo para que el dicho Juan Pérez trajese al dicho Morillo a su obispado [de Tortosa] y que esto le parece que se lo dijo m[aest]re Juan de Santangel y así tengo sospecha que toda esta gente son una liga».

24. Aparecen varios Juan o Johanes Pérez en las listas de graduados del colegio de San Ildefonso de Alcalá, nombre con el que firmaba sus obras, pero era relativamente común. Sin embargo, no hay ningún Pérez de Pineda entre ellos. AHN, Univ., libro 397. Sobre el calvinista andaluz, ver Kinder, 1986a; Kinder, 1986c, p. 85-96. Elementos actualizados de su biografía en Boeglin, 2008, p. 57-75.

25. Redondo, 2001; Boeglin, 2007, p. 102-103; Pastore, 2010, p. 292-301; Civale, 2008, p. 146-198.

26. Kinder, 1986b, p. 196-197. Deposiciones de Jaime Sánchez.

27. Tellechea, 1963a, p. 852. Ver también Tellechea, 1967, p. 35-51; Kinder, 1978, p. 345-350. 
Iglesia católica en varios puntos esgrimidos por Lutero y los reformados, se formó y se afianzó su sensibilidad religiosa. Posteriormente, tomó una postura más abiertamente protestante. Considerado como luterano por muchos españoles, no lo negaba y declaró a varias personas que si tenía los errores de Lutero, se los debía a las enseñanzas de fray Bartolomé Carranza y del cardenal Reginaldo Pole (Tellechea, 1963a: 561, 564).

Los inquisidores de Zaragoza barajaban la posibilidad de que Pérez de Pineda hubiese salido del reino a buscar a Morillo a petición del Doctor Egidio, para que fuera a asistirlo en el obispado de Tortosa, donde había de ser nombrado ${ }^{28}$. El nombramiento fue postergado y anulado, al iniciarse el proceso por herejía contra el canónigo magistral de Sevilla. En París, donde estuvo hasta 1553, Morillo acogía a los españoles de paso o a los estudiantes, y tuvo gran influencia sobre ellos, según el testimonio hecho a los inquisidores por Baltasar Pérez (Tellechea, 1963b: 35-36; Kinder, 1986b: 173-174). Sin lugar a dudas, Morillo ya había abrazado el protestantismo desde su estancia parisina, tras haber compartido en Italia las posiciones del partido de los espirituali favorables a un acercamiento entre católicos y protestantes.

Monterde había compartido estas mismas visiones y es posible que Morillo lo introdujera en el círculo de los cardenales abiertos a un diálogo con los reformados en 1546 y 1547, cuando estuvo en Roma. Antiguo profesor de Morillo, el rector le había enseñado a leer y había sido luego su amigo. Ambos coincidieron en Flandes, según declaró a los jueces, pero probablemente también en Roma ${ }^{29}$. Compartía la misma sensibilidad que abogaba por una reforma eclesiológica y dogmática encaminada a facilitar el retorno de los reformados al seno de la Iglesia. Pero ante los jueces prefirió afirmar que, si había tenido estrecha amistad con Morillo desde que había sido su estudiante, había dejado de tener trato con él después de que huyera de la justicia del rey de Francia en 1553, que le perseguía por presuntos cargos de luteranismo ${ }^{30}$. Aún así, a pesar de afirmar conocer poco a Pérez de Pineda, Monterde sabía los lazos estrechos que le unían a Morillo y le transmitió las informaciones facilitadas por el doctor Arnedo, obispo de Mallorca, que, en una carta, le había dado cuenta de la muerte de su amigo en Estrasburgo, camino a Francfort, «hereje y atosigado» ${ }^{31}$, es decir, envenenado, en 1555 . En su respuesta, en la primera carta traída por Julián Hernández, Pérez le confirmó su fallecimiento ${ }^{32}$.

Cercano a este grupo de aragoneses abiertamente favorables a la confesión reformada, Francisco Mudarra constituía otro personaje central con quien el rector mantuvo una correspondencia epistolar. Éste había sido acusado en Roma por Ignacio de Loyola de defender puntos de vista heréticos y tuvo que huir de la ciudad eterna para escapar al Santo Oficio (Kinder, 1986c: 89). Como había sido procesado in abstentiam por la Inquisición romana, los inquisidores zaragozanos

28. AHN, Inq., libro 961, f. 532v.-533r. (28.9.1558).

29. AHN, Inq., leg. 3570, caja 1, Méritos..., f. 7r.

30. Ibídem, f. 7r.

31. Ibídem, f. 6v.-7r.

32. Ibídem. La respuesta de J. Pérez fue publicada por Kinder, 1986c, p. 85-96. 
pidieron al Consejo que se examinara el proceso en vistas a acumular elementos que permitieran inculpar a Monterde, pues habían hallado una carta en que Mudarra había hecho «befa del Purgatorio» ${ }^{33}$.

Monterde también había estado cercano a otro aragonés ilustre y perseguido por cargos de luteranismo, Mateo Pascual, rector del colegio de San Ildefonso de Alcalá entre 1528 y 1529. Siendo rector, se había reunido en su despacho la comisión nombrada por el inquisidor general Manrique para pronunciarse sobre el Diálogo de la doctrina cristiana, de Juan de Valdés. Compuesta por Mateo Pascual, por el canciller Pedro de Lerma y otros profesores, la junta había dictaminado a favor de la edición de la obra ${ }^{34}$. Poco después, el rector del colegio de San Ildefonso hubo de huir y se reunió con Juan de Valdés en Roma. Volvió a los pocos años a Aragón como vicario general de Zaragoza, a partir de 1532, poco antes de ser detenido y juzgado en Toledo, en julio de $1533^{35}$. Se desconoce la sentencia pronunciada entonces contra el maestro Pascual, probablemente una penitencia por palabras sospechosas de luteranismo o alumbradismo ${ }^{36}$. Aquella condena no le impidió volver a sus funciones de vicario general, reintegrado por el nuevo arzobispo don Hernando de Aragón a su cargo, que ocupó pocos meses, entre noviembre de 1539 y agosto de $1540^{37}$. En los últimos tiempos de su mandato, el maestro Pedro Serra, «consejero» del Santo Oficio de Zaragoza, escribía una carta pidiendo el amparo del tribunal en julio de 1540:

No creo ignoran Vuestras Señorías el mucho daño que poco a poco puede hacer el letrado que siente mal de la santa fe católica: y como el doctor Pascual haya sido penitenciado por proposiciones y aserciones repugnantes a la determinación de la Iglesia y en lugar de contenerse, no cese de sembrar obras del mismo jaez de las sembradas antes, porque lo he reprehendido, en pláticas y disputas entre él y mí pasadas, de ellas ante testigos fidedignas, de ellas a solas, y le tengo cogidas algunas diabólicas, por anular mi dicho temiendo que depuse contra él, como lo he hecho ante el inquisidor Molón, anda buscando modas como afrentar mi persona con el poder que tiene de vicario general por el Señor Arzobispo. Y habiendo servido de consejero mas de diecisiete años al Santo Oficio en este reino, no habiendo pedido en todo este tiempo el amparo y sabor del que a los que se sirven acostumbra dar, ahora me es forzado pedirlo ${ }^{38}$.

Las luchas internas fueron en contra del doctor Pascual, quien, cuando perdió el apoyo de sus protectores, abandonó su cargo en el mes siguiente y, para huir de nuevas pesquisas inquisitoriales, prefirió retirarse a Roma, donde murió en $1553^{39}$.

33. AHN, Inq., libro 961, f. 532v.-533r. (28.9.1558).

34. Bataillon, 1991, vol. I, p. 514; Pastore, 2010, p. 264.

35. AHN, Inq., libro 321, f. 136r. (15.7.1533).

36. Ver la nota 15. Ver también la carta del maestro Serra, citada a continuación.

37. Fernández Serrano, 1969, p. 51.

38. AHN, Inq., libro 961, f. 164r., carta de 29 de julio de 1540. Agradezco a David Kahn dicha referencia inédita tocante a Mateo Pascual.

39. M. Bataillon apuntaba la fecha de 1553 para la muerte de M. Pascual: Bataillon, 1991, vol. I, p. 515517. Lo confirma el epitafio del humanista Juan de Verzosa. Ver Verzosa, 2006, vol. I, XXXII, p. 83. 
El rector Miguel Monterde aparecía, así, como un reo altamente sospechoso a ojos de los inquisidores, por su correspondencia y su trato con aragoneses que se habían adherido al protestantismo o que habían compartido ciertos planteamientos de los reformados. Pero, más que estas relaciones y las testificaciones comprometedoras de Julián Hernández, eran las cartas de Juan Pérez de Pineda, traídas por Julianillo u otros portadores, como Domingo Ferrán, las que dificultaban su causa (Kinder, 1986b: 177). Estas diez cartas incautadas delataban, según los inquisidores, «la gran amistad» e «inteligencia» que había entre ellos. La correspondencia duró de mayo de 1555 a agosto de 1556, cuando Juan Pérez mandó la quitanza del dinero recibido ${ }^{40}$.

$$
* * *
$$

Iniciada a favor de la petición del maestro Juan Santángel, la correspondencia revelaba, en efecto, la gran familiaridad entre ellos, por el número de conocidos comunes evocados, desde el Doctor Egidio en Sevilla hasta Francisco Mudarra o Juan Morillo. Dichas misivas confirmaban como Pérez de Pineda, tras la huida forzosa de Morillo en 1553, fue sustituyéndole y se convirtió en el polo de atracción de muchos exiliados y estudiantes españoles en París, como Jaime Sánchez, Pere Lluís Berga o Martín de Bervete. Éste último, zaragozano, matriculado en la Universidad de París, había sido instruido en las doctrinas evangélicas por Juan Pérez. En una misiva a Monterde, el discípulo del Doctor Egidio exiliado lo presentaba como uno de los pocos españoles del exilio de quien el rector podía fiarse, y señalaba que a él «Vuestra Merced podrá enderezar las cartas y no a otros porque es vere pius [sic] de quién yo me fío como de mí mismo y conoce a Vuestra Merced como hijo del Evangelio por las noticias que le he dado ${ }^{41}$. Bervete servía, así, de destinatario a los correos enviados a Pérez de Pineda, para impedir que fueran interceptados por agentes españoles y, para limitar los riesgos, el calvinista andaluz aconsejaba, en una de las cartas a Monterde, que no firmara sus misivas o lo hiciera con otro nombre y que mudara su escritura ${ }^{42}$. La atmósfera en los círculos exiliados, como lo revelan las misivas de Pineda, estaba marcada por el acecho y la desconfianza, en particular tras las detenciones de exiliados y las muertes de Juan Díaz o de Morillo, asesinados, cuando escribía, en 1555 o 1556, «no hay aquí españoles de quienes fiar sino de él, porque los demás son malignos y de natura perversa $»^{43}$.

Procedía Bervete de una familia zaragozana y su padre «aborrecía el Evangelio», según Pineda, frase en cifra para señalar que no compartía en nada la profesión de fe secreta de su hijo. El joven estudiante también mantuvo una correspondencia con Monterde en los mismos años. Los inquisidores hallaron seis cartas de Bervete entre los efectos personales del rector y, en una de ellas,

40. Dos de ellas fueron editadas por Kinder, 1986c, p. 93-96. Dadas las fechas proporcionadas por el documento inquisitorial, no consta, entre las diez cartas, la de J. Pérez que debía de haber traído Julianillo en su viaje de primavera de 1557.

41. AHN, Inq., leg. 3570, caja 1, Méritos..., f. 5v.

42. Ibídem, f. 4r.

43. Ibídem, f. 5v.-6r. Sobre el acecho a los exiliados, ver Truman y Kinder, 1979, p. 65-93. 
le anunciaba la vuelta de Julianillo: «Julián llegó aquí muy bueno y besa las manos de V.M.» y, dándole diversas noticias sobre Juan Pérez, acababa la carta «rogando al Señor la vida de V. M. alargue por muchos años y que haya muchos en Aragón que imiten a V. M. a buscar la honra y gloria de Dios» ${ }^{44}$. Unas palabras suficientemente equívocas que venían a recargar el expediente de Monterde. En otra carta, daba cuenta de la salida de Juan Pérez para Flandes para llevar a cabo la impresión de la traducción del Nuevo Testamento, que deseaba ver finalizada cuanto antes. Posteriormente, le mandó al rector un libro de cuyo título Monterde afirmó a los jueces no acordarse y que, al poco tiempo, acabaría siendo prohibido por un edicto de la Inquisición. El rector le escribió entonces dándole cuenta de ello y aconsejándole que, si venía a España, dejara de tener conversación con personas sospechosas y se guardara de leer este tipo de literatura religiosa ${ }^{45}$. Más tarde, Martín de Bervete iba a ser ordenado ministro protestante y sus actividades llamarían la atención del embajador español en París (Kinder, 1986c: 90-91).

A través de Pérez de Pineda, Monterde también había entrado en contacto con otro aragonés, Felipe de la Torre, natural de Tarrazona, al que el calvinista andaluz describió como «vere theologus, hombre de mediana estatura, moreno, al cual unice amo propter pietatem quam Dominu animo illius insevit ministerio evangelii pasará por allí y hablará con V. M. como consorte» ${ }^{46}$. De la Torre, que se había graduado en Artes en Alcalá en 1544, había estado luego el mismo año en París con Morillo, al que siguió a Lovaina y participó en el círculo protestante de Pedro Jiménez (Tellechea, 1963b: 28-31). El calificativo «consorte» resultaba ya de por sí comprometedor y más aún en vistas de la testificación de Julián Hernández, quien declaró que Juan Pérez le había referido que «Felipe de la Torre tiene los dogmas luteranos» porque se los había enseñado y catequizado ${ }^{47}$. Felipe de la Torre, que en aquellos años ya había publicado la Institución de un príncipe cristiano, logró más tarde volver desde Lovaina hasta España, posiblemente gracias a valiosos valedores y a una confesión hecha ante los inquisidores (Truman, 1984: 83-93). Su caso parece haberse tramitado rápidamente y pudo volver a España sin dificultades aparentes, pues fue capellán del rey (Tellechea, 1963b: 37). Cuando fue interrogado en el marco del proceso de Bartolomé Carranza, prefirió limitarse a afirmar, a propósito de Juan Pérez de Pineda, que sólo sabía que había estado corrigiendo la traducción del Nuevo Testamento de Enzinas y que había procurado inducir a Morillo a apartarse de sus errores luteranos. En sus declaraciones, nombró a muchos amigos de éste ${ }^{48}$.

Cuando ya habían salido de las prensas de Jean Crespin, en Ginebra, los últimos opúsculos editados por Juan Pérez de Pineda, Julián Hernández emprendió

44. AHN, Inq., leg. 3570, caja 1, Méritos..., f. 6r.

45. Ibídem, f. 9v.

46. AHN, Inq., leg. 3570, caja 1, Méritos..., f. 8r.-8v. Ver también la carta de Pérez de Pineda en Kinder, 1986c, p. 96.

47. AHN, Inq., leg. 3570, caja 1, Méritos..., f. 8v.; Kinder, 1986b, p. 180-181.

48. Tellechea, 1963a, vol. II.2, p. 851-853; Tellechea 1963b, p. 31. La traducción editada por Pineda contiene notables diferencias con respecto al texto de Enzinas. Muy probablemente lo utilizara para realizar su propia traducción. 
un segundo viaje que había de llevarle hasta Sevilla. De camino, pasó por Zaragoza, para dar muestra de los ejemplares que se habían publicado gracias, en parte, al donativo de Santángel tramitado por el rector y a entregarle algunos. Monterde comprobó los libros que llevaba Julián Hernández en su talego y, por el testimonio del rector, sabemos precisamente cuáles fueron los libros llevados a Sevilla y su número. Eran unos catorce o quince ejemplares del Testamento Nuevo ${ }^{49}$ que había hecho imprimir Pérez de Pineda «y otros tantos salterios» ${ }^{50}$, junto con la Carta para el Rey de España y la Imagen del Anticristo ${ }^{51}$. Junto a éstos, se hallaban seis o siete catecismos ${ }^{52}$ de Calvino traducidos y adaptados por Juan Pérez de Pineda y una Institución de Calvino con que Julianillo debía de obsequiar a Monterde.

Algunos, como los Salmos de David, acababan de salir a principios de 1557 de las prensas de Crespin en Ginebra, y Julianillo cruzó Francia para ir a Aragón y a Sevilla a distribuirlos. El proyecto que se proponía Juan Pérez con dichas traducciones y ediciones era sacar a España de las tinieblas en las que estaba, según él. En una carta al rector, escribía: «en tanto que el Señor me dejare en este mundo, tengo propósito y voluntad de emplearme en ayudar a mi nación con lo que el Señor me ha dado [...] [porque] nuestra nación está más pobre y más miserable de las tierras que profesan cristianismo, y así tiene necesidad de ser ayudada con mayor piedad, pues es tan crecida su miseria» ${ }^{53}$. Según declaró Monterde ante los jueces, dichas palabras le habían sentado mal, «porque le oyó decir que acá no sabían letras, ni se conocía a Dios ni entendía el Evangelio» ${ }^{54}$. No obstante, habían seguido carteándose y debió de compartir con Juan Pérez sus proyectos editoriales de catecismos en castellano, pues Monterde le aconsejó que «si escribiese algo, lo hiciera de forma que fuese acepto en España y que lo hiciese con autoridades de la Iglesia», pues, según él, la «Doctrina Grande de Constantino no agradaba a muchos porque no probaba con autoridades lo que decía» ${ }^{55}$.

49. El Testamento Nuevo de nuestro Senor y salvador Iesu Christo. Nueva y fielmente traduzido del original Griego en romance Castellano. En Venecia, en casa de luan Philadelpho, MDLVI [Ginebra, 1556].

50. Los psalmos de David con sus sumarios, en que se declara con brevedad lo contenido en cada Psalmo, agora nueva y fielmente traduzidos en romane Castellano por el doctor Iuan Perez, conforme a la verdad de la lengua Sancta [...] En Venecia en casa de Pedro Daniel. MDLVII [Ginebra, 1557].

51. [Pérez de Pineda, Juan] Carta embiada a nuestro augustissimo senor principe don Philippe, Rey de España en que se declaran las causas de las guerras y calamidades presentes... [Ginebra, 1557]. [Ochino, Bernardino], Imagen del Antechristo, conpuesta primero en italiano y despues traduzida en romançe por Alonso de peña fuerte [Ginebra]: [Jean Crespin, 1556?]. Alonso de Peñafuerte fue probablemente el seudónimo usado por Pérez de Pineda. Véase Bonnant, 1962, p. 50-57.

52. Sumario breve de la doctrina Christiana hecho por via de pregunta, y respuesta, en manera de coloquio, para que assi la aprendan los niños con mas facilidad, y saque della mayor fructo Compuesto por el Doctor Juan Perez. Fue impresso en Venecia, en casa de Pietro Daniel, MDLVI [Ginebra, 1556]. Reedición a cargo de Usoz y Río, 1852, RAE, VII.

53. AHN, Inq., leg. 3570, caja 1, Méritos..., f. 3v.

54. Ibídem, f. $5 \mathrm{v}$.

55. Ibídem, f. 5r.-v. La Doctrina grande de Constantino era la Doctrina cristiana en que esta comprendida toda la información que pertenece al hombre que quiere servir a Dios, por el Doctor 
En efecto, si la obra del doctor Constantino de la Fuente aparentaba conformarse con la doctrina cristiana, hasta tal punto que los inquisidores le dieron licencia para imprimirla, desarrollaba en profundidad, como su Suma de la doctrina, de 1543, temas afines a los planteamientos de Juan de Valdés y de los reformados alemanes y franceses ${ }^{56}$. Escritos, en su mayoría, en un periodo anterior al inicio del Concilio de Trento y a la aprobación de los decretos sobre la justificación, en un ambiente en que podía esperarse aún ver converger las posiciones de la Iglesia romana hacia planteamientos dogmáticos que permitieran la reunión de todos los cristianos, los libros del predicador de Sevilla empezaron a ser el objeto de las suspicacias de los sectores tradicionalistas y de los inquisidores a partir de su vuelta de Flandes en 1553. Las obras del doctor Constantino mostraban una innegable influencia de los autores reformados alemanes, suizos y alsacianos, como Melanchton, Zwinglio o Bucer, de marcada sensibilidad irénica en sus planteamientos y, en cuestiones como la de los sacramentos, la justificación por la gracia o el papel de las obras para la salvación de los fieles, manifestaba una postura intermedia muy afín a las posturas del partido católico reformado italiano, los spirituali. Su catecismo dialogado, la Suma de doctrina cristiana, escrito poco después de la dieta de Ratisbona de 1541, dejaba traslucir este espíritu de concordia entre cristianos, proponiendo una economía sacramental reducida a la más mínima expresión y rehuyendo de la cuestión de las obras.

El catecismo traducido al castellano por Juan Pérez de Pineda era una adaptación de la catequesis calvinista dirigida al público español. Por esto, cuando Julián Hernández trajo su talego de libros a España, Juan Pérez le había encomendado que dejase a Monterde los libros que quisiese escoger, ya que el motivo del viaje era dar muestra de lo que se había editado en Ginebra. Los catecismos de Pérez de Pineda podían quedarse todos en manos del rector en Aragón o entregarse allí «a quien los quisiese», según tenían acordado el reformista andaluz y Julianillo, dado que «en Sevilla había la Institución y Catecismo de Constantino, porque, en efecto — - según puntualizó Hernández-, todo lo que se contiene en el catecismo de Juan Pérez se contiene en los escritos de Constantino y que en Aragón se distribuirían mejor los catecismos de Juan Pérez» ${ }^{57}$. No deja de ser evocador que la obra de Constantino se confundiera con la Institución de Calvino, cuando se trataba seguramente de la Doctrina cristiana comúnmente llamada

Constantino. Parte primera. De los artículos de la fe (1548, Sevilla, Juan Canalla; con «examen y licencia de los muy reverendos señores inquisidores del arzobispado»). Reeditado en 1554 y 1555 en anverso. Las dos otras partes nunca salieron a luz.

56. Constantino de la Fuente, Suma de doctrina christiana en que se contiene todo lo principal y necesario que el hombre christiano deve saber y obrar, Sevilla, 1543 [reeditado en 1544, 1545, 1547 y 1551$]$.

57. AHN, Inq., leg. 3570, caja 1, Méritos..., f. 9r. ¿Se trata de un error del notario del secreto a la hora de recopilar los datos del proceso en la relación de méritos o del propio Hernández en su deposición? No se tiene constancia de que circulara en Sevilla la Institución de la religión cristiana de Calvino y probablemente haya que atribuir dicha afirmación a la asimilación de la obra de Constantino a la opera magna calviniana. 
Doctrina grande, en la que el predicador pretendía abordar las materias de la fe desde los doce artículos de fe, integrándolos dentro de la historia de la Revelación, con amplias consideraciones sobre la resplandeciente verdad de la fe cristiana y las tribulaciones del Evangelio a través de la historia ${ }^{58}$.

En ella, desarrollaba una eclesiología muy cercana a la de Zwinglio, en su oposición entre la Iglesia universal y la Iglesia santa (o invisible, en la teología del reformador suizo), entre la Iglesia de los creyentes, con sus miembros muertos y podridos que se limitaban a seguir los preceptos, y la de los verdaderos justos y elegidos, animados por el Espíritu Santo. Esta concepción pneumatológica (del griego pneuma, que significa 'espíritu', 'hálito') permitía desarrollar el concepto de la Iglesia santa y pequeña en la que se reunían los verdaderos fieles ${ }^{59}$. A partir de la misma definición de la Iglesia santa, definía la comunión de los santos en la Doctrina Cristiana de 1548, en el sentido que le prestaban los reformados, como solidaridad entre los miembros de esta comunidad ${ }^{60}$. Su planteamiento era muy cercano al que Calvino exponía en su Institución de la religión cristiana. Según la definición dada por Constantino, la comunión de los santos dejaba de ser el lazo trascendente que reunía a los fieles vivos y muertos en la unidad de un mismo cuerpo místico cuya cabeza es Cristo. El predicador evitaba, así, tener que pronunciarse sobre el nexo de justificación a la relación entre Iglesia triunfante, purgante y militante y sobre el papel intercesor de los santos que defendía la doctrina romana desde la edad media.

En torno al papel de las obras, de los méritos de Cristo o de los sacramentos (reducidos a tres: bautismo, eucaristía y confesión — los más esenciales-,y no a dos, como en Calvino), la obra constantiniana, desde la Suma de Doctrina, de 1543, hasta la Doctrina cristiana o Doctrina grande, de 1548, manifestaba unas concepciones eclesiológicas y teológicas cercanas a la confesión de Augsburgo o, por lo menos, compatibles con ésta.

58. Se inspiraba en gran parte de la obra del irenista alemán Georg Witzel (1501-1573), cercano a Lutero un momento dado y que luego se convirtió en un acérrimo denunciador de los excesos de los protestantes. Lamentaba, al mismo tiempo, que la interpretación rigorista de los cánones de Trento imposibilitaran en adelante cualquier acercamiento entre las dos confesiones. Sobre las similitudes de la Doctrina grande con el Catechismus ecclesiae, de 1533, ver Guerrero, 1969, p. 166-167.

59. Doctrina cristiana..., f. 264r.-266v.

60. Doctrina cristiana..., f. 268r.-v.: «lo que llamamos en una parte santa iglesia, llamamos en la otra santos, cuando decimos comunión de santos, porque de los miembros santos es constituido el cuerpo de la iglesia santa. Cuando decimos que hay comunión de santos, entendemos estar estos miembros unidos entre si con grandísima victoria. De manera que comunión de santos es la condición y la inclinación de la Iglesia santa [...] Como tienen una cabeza, tienen una fe y una obediencia y un amor, viene a que sean todos un cuerpo y que tengan comunión entre sí. Decimos pues que por comunión entendemos aquí participar todos de unos mismos beneficios y de una mismas mercedes y tener una liberalidad unos con otros tan grande y tan extendida que no hay cosa partida entre ellos». 
Si Monterde no parece haber conocido personalmente al doctor Constantino de la Fuente, sino por sus escritos, mantuvo, en cambio, estrechas relaciones con su antiguo maestro, el Doctor Egidio, incluso después de su condena como hereje en 1552. El canónigo magistral de Sevilla era natural de Olvés, en Aragón ${ }^{61}$, y el rector siguió en estrecho contacto con su profesor de Artes y Filosofía en la Universidad Complutense y mantuvieron una correspondencia epistolar, intercambiando escritos. Cumplida su sentencia de 1552, Egidio había solicitado la autorización del cabildo sevillano de ausentarse para volver a su tierra en mayo de 1554, y allí permaneció una temporada, hasta el mes de octubre de $1555^{62}$. Monterde le recibió durante unos quince días en Villanueva de la Huerva, donde regentaba su rectoría, y allí tuvieron entera libertad para evocar la situación religiosa en Sevilla y en el resto de la Península tras la condena del predicador.

Los largos meses de su estancia en sus tierras, cuando decidió alejarse del ambiente bochornoso de Sevilla, debieron de ser aprovechados por el canónigo magistral para propagar en Aragón la concepción de la fe que defendía y relacionarse más estrechamente con sus antiguos discípulos, incluso aquellos que se encontraban en el exilio, como Juan Pérez de Pineda. Egidio aprovechó después un viaje como delegado del cabildo catedralicio en mayo de 1555 para reunirse con sus discípulos y con los miembros del ala reformada española, particularmente en Valladolid, y se entrevistó con Carlos de Seso, Pedro Cazalla y su hermano Agustín Cazalla, el cabecilla de la comunidad criptoprotestante de Valladolid, otro amigo de Miguel Monterde desde tiempos de sus estudios en Alcalá.

Ante los jueces, prefirió Monterde limitarse a evocar charlas generales con su antiguo maestro sobre su situación después de la condena y sus escritos. Por las confesiones hechas por Julián Hernández a los jueces, estuvo obligado a detallar lo que Egidio le había contado, en particular:

[...] le dijo que había escrito sobre Los Reyes y traducido los Reyes y otras obras sobre la Sagrada Escritura y que otras escrituras se le habían quedado en la Inquisición cuando estuvo preso; y que en un monasterio de Cartujos escribió también cuando estuvo y que él [el rector] nunca vio cosa suya sino el Psalmo de profundis en romance que traía un criado del dicho doctor, llamado Domingo Pérez, y dice que no se acuerda si rogó al dicho doctor que le enviase de lo que había escrito. Y después, con un hermano suyo clérigo, envió un salmo que cree que era In te $d$ [omin]e esperavi que era en romance y que no sabía lo [sic] que lo había hecho y que el dicho Monterde envió al dicho doctor un comentario sobre el Éxodo o sobre el Levítico en latín que el dicho Juan Pérez le había enviado de París en un envoltorio de $\operatorname{cartas}^{63}$.

A su vuelta de Valladolid, el 6 de junio de 1555, Egidio, pocos meses antes de fallecer, envió, desde Sevilla, una carta al rector en la que traslucía que tam-

61. Transcrito «Olvera» por error en la relación del auto de fe de 1560, en que fueron quemados sus huesos: AHN, Inq., leg. 2075, exp. 1.

62. Hazañas, 1909, ap. 2, p. 384.

63. AHN, Inq., leg. 3570, caja 1, Méritos..., f. 8r. 
bién Monterde tramitaba gestiones en su nombre, tal vez envíos de dinero para participar en la financiación de las ediciones que llevaba a cabo Pérez de Pineda desde París ${ }^{64}$.

Las declaraciones de Hernández resultaban tanto más arriesgadas para el rector Monterde que afirmaba que éste le había dicho que «el dicho doctor [Egidio] decía que los inquisidores le habían atajado el camino por una parte defendiéndole que no predicase pero que no por tanto dejaba de aprovechar por los escritos y confesiones», y puntualizó «que entendió el dicho Julián que el dicho Monterde y el doctor Egidio entendían por estas palabras aprovechar que era aprovechar en la religión y dogmas luteranos» ${ }^{65}$.

También fue Monterde quien había anunciado a Juan Pérez la muerte de Egidio. El exiliado contestó a su corresponsal:

No sé si me digo que fue mayor el alegría que recibí del buen Doctor que la pena, porque estando en tal disposición como estaba y le habían puesto los que aborrecen la Cruz es justo que nos alegremos antes de su bien, que no tengamos pesar por su ausencia; ya descansarán ahora los que no quieren que alumbre el sol, ni reciban vista los ciegos; para que vean y conozcan al que dio su vida por ellos, si hombres faltasen, que descubran quién es Jesucristo, las piedras se levantarán a publicarlo.

Escribían los inquisidores a continuación: «y así a este tono va cerca de una plana de papel de letra menuda siempre diciendo muy grandes loores del dicho Doctor y de sus cosas y vida y al fin dice: Dándome el Sr. vida, no me quedará por diligencia de sacar luz lo que de sus trabajos pude haber ${ }^{66}$. Monterde se propuso recuperar las obras de su antiguo maestro y entregárselas a Pérez de Pineda para que las publicara «pues le había dicho que había dejado algunas cosas escritas». No obstante, a pesar de las misivas mandadas a un criado de Egidio, un cierto Domingo Pérez, el rector afirmó a los magistrados no haberlo conseguido ${ }^{67}$.

Por sus relaciones con muchos reos sospechosos de luteranismo, y entre ellos los principales acusados de Sevilla y Valladolid, y por su correspondencia con Pérez de Pineda y miembros de su círculo en París, el expediente de Miguel Monterde aparecía bastante recargado y voluminoso. Las últimas declaraciones hechas por Julián Hernández le pusieron en otro aprieto, en particular cuando el castellano afirmó, a modo de epílogo en sus confesiones ante los inquisidores,

64. Ibídem, f. 7v.: Según los fragmentos reproducidos en la relación de méritos, la carta de Gil decía «no he respondido antes a V. M. antes de ahora esperando cierto despacho que había oído decir que el rector Monterde $[s i c]$ era que tenía ordenado se hiciese para V. M.», y proseguía: «plúgome saber que el primer despacho fuese a salvo y como yo lo ordené que mi hermano lo llevase y asimismo con la nueva que V. M. me dio de lo demás que me había de remitir, nuestro Señor lo encamine».

65. AHN, Inq., leg. 3570, caja 1, Méritos..., f. 7v.

66. Ibídem, f. 7r.-v. Ver también el libro 961, f. 563v. (9.9.1558): «entre estas cartas hay una del dicho Juan Pérez en loor del doctor Egidio que por el voto de éste bien le canonizara, es cosa de ver con qué desvergüenza habla».

67. Ibídem, f. 8r. El autor de las Artes de la Inquisición afirma, no obstante, tener recuperados escritos de Juan Gil que se disponía a publicar (Castrillo, 1991, p. 435-437). 
que «del rector Monterde no puede decir otra cosa por lo que de él oyó decir y coligió, como dicho tiene, sino que aprueba y favorece generalmente la religión que los luteranos tienen y enseñan y desea saber y vivir conforme a ella» ${ }^{68}$.

Monterde negó rotundamente aquellos cargos de la misma forma que desmintió haber recibido algún libro por parte de Julián y se limitó a reconocer conversaciones mantenidas con él sobre diversos temas, como, por ejemplo, la situación religiosa en los países nórdicos. El 22 de mayo de 1559, los inquisidores de Zaragoza anunciaban al Consejo que el rector seguía negativo en la parte sustancial de la causa y dudaban entre despacharla o seguir esperando para acumular nuevos cargos contra él. El Consejo se limitó a contestar que se hiciese justicia sin consideración de su persona, sino de sus delitos ${ }^{69}$.

Desde tales perspectivas, con numerosas imputaciones de luteranismo, fue condenado a abjurar de vehementi, pero no reconciliado, ante la imposibilidad para los inquisidores de hallar testigos contestes, es decir, que coincidieran en los cargos reunidos contra él. A la sentencia espiritual, se añadía una pena de diez años de reclusión en el monasterio de San Francisco de Zaragoza, en el que entró a cumplir su condena el 28 de julio de 1560, al cabo de un proceso que había durado aproximadamente dos años. También tuvo que pedir prestado dinero a sus amigos para pagar una multa de 2.000 ducados. Los numerosos testigos que pudo presentar a su favor eran «en abono de su persona así en general de ser buen cristiano, como de haber hablado siempre bien de las cosas de la religión católica cristiana», y haber estado siempre en la obediencia de la Iglesia romana y haber tenido en su casa y venerado imágenes del Señor, de la Virgen y de haberse confesado y comulgado notoriamente «y otras cosas de católico cristiano $»^{70}$, pero, como lo muestra la sentencia, no logró convencer a los jueces de la ingenuidad de su actuación.

Al poco tiempo de empezar a cumplir su condena, otra causa fue abierta después de que su sobrino le acusase de mantener una correspondencia con una mujer y usar términos en las cartas que dejaban sospechar que fuera casado con ella. Fue encarcelado otra vez e interrogado por los inquisidores, por lo que podía asimilarse a un rechazo al voto de celibato. Fue absuelto de los cargos del segundo proceso y su sobrino condenado por falso testimonio ${ }^{71}$.

Al cabo de cuatro años y medio, el licenciado Antonio de Molina, miembro del tribunal zaragozano, que afirmaba temer por la salud del rector, muy deteriorada después de su segundo paso por los calabozos de la Inquisición, y movido por la buena actitud de penitente, así como por los testimonios a su favor de los religiosos del convento donde cumplía su pena, propuso al Consejo que el resto de la pena de reclusión se ampliara al conjunto de la capital zaragozana y hasta Villanueva de la Huerga, para que pudiese acudir a su rectoría. Puesto que contaba con el apoyo del obispo de Cuenca, fray Bernardo de Fresneda, que intervino

68. AHN, Inq., leg. 3570, caja 1, Méritos..., f. 7v.-8r.

69. AHN, Inq., libro 961, f. 546: «la causa del rector Monterde esta ya después del auto conclusa; por él no parece tiene entera probanza del todo para le tener por convencido porque está negativo en mucho de lo sustancial».

70. AHN, Inq., leg. 3570, caja 1, Méritos..., f. 10r.-10v.

71. Ibídem, f. 10v.-11r. Ver Kinder, 1986b, p. 186. 
en dos ocasiones en su favor y, según parece, de miembros del tribunal zaragozano, el Consejo accedió a la petición y, en 1566, le levantaron la pena de reclusión y de prohibición de decir misa y administrar sacramentos ${ }^{72}$. Murió pocos años después, en 1571 (Gómez Uriel, 2001: 348).

$$
* * *
$$

El proceso Monterde confirma las múltiples conexiones existentes entre Zaragoza, París y Sevilla y la estructura de los cenáculos secretos en la Península, estrechamente vinculados a la persona del Doctor Egidio, verdadero propagador de los principios de la Reforma desde el tiempo de su magisterio en Alcalá. Los fragmentos de esta causa señalan, además, el sistema de recaudación de fondos para financiar la edición de textos de propaganda reformada en Ginebra y el papel central desempeñado por Juan Pérez de Pineda a través del círculo de su maestro de Sevilla. La suerte de Monterde es reveladora, por fin, del destino de aquellos humanistas partidarios de una conciliación o una concordia con los protestantes que, al finalizar las primeras sesiones del Concilio de Trento en 1547 y a su reapertura en 1551, resultaban cada vez más aislados y al margen de la Iglesia. En una década, entre 1542 y 1552, los bloques confesionales se habían consolidado y las expectativas pasaban a ser, en primer lugar, el exilio, como fue el caso de Pérez de Pineda, Juan Morillo, Mateo Pascual y también muchos de los monjes isidros de Sevilla. Otra opción que se presentaba era la organización bajo la forma de cenáculos secretos, como en Valladolid y Sevilla, en círculos reducidos, siempre expuestos a una posible denuncia, o en Valencia, donde perduraron hasta la década de 1570. O, por fin, la última posibilidad era procurar abandonar sus íntimas convicciones para conformarse con los nuevos principios asentados por la Iglesia romana, como parece haber sido el caso del rector Monterde, culpable a pesar de mostrar un acatamiento a los ritos y observancias externas de la fe católica, de no haber cortado las relaciones con aquellos con quienes había compartido una sensibilidad religiosa que resultaba, en adelante, inconciliable con el catolicismo tridentino.

\section{Bibliografía}

Almenara, M. y Ardit Lucas, M. (1998). «El protestantisme valencià del segle Xvi: Una nova perspectiva». El Contemporani: Revista d'Història, 16, 31-35.

Andrés de Uztárroz, J. F. (1680). Progressos de la Historia en el Reyno de Aragón y elogios de Gerónimo Zurita su primer coronista... contienen varios sucesos desde el año MDXII hasta el de MDLXXX.... Zaragoza: Hdes. de Diego Dormer.

Bataillon, M. (1991). Erasme et l'Espagne. Ginebra: Droz. 3 vol.

Boeglin, M. (2007). Inquisición y Contrarreforma: El tribunal del Santo Oficio de Sevilla (1560-1700). Sevilla: Renacimiento.

- (2008). «Les Épîtres à Philippe II de Pérez de Pineda et de Corran: Une apologie de la liberté de conscience». En: PARello, V. (ed.). Actas del coloquio La correspondance,

72. AHN, Inq., leg. 3570, caja 1. Carta sin fecha, recibida en Madrid el día 13 de febrero de 1566. 
pratiques et usages sociaux. Montpellier, 24-25 de abril de 2007. Pau: Presses Universitaires, $57-90$.

Bonnant, G. (1962). «Notes sur quelques ouvrages en langue espagnole imprimés à Genève par Jean Crespin (1557-1560)». Bibliothèque d'Humanisme et Renaissance, XXIV, 50-57.

Castrillo Benito, N. (ed.) (1991). El «Reginaldo Montano»: primer libro polémico contra la Inquisición española. Madrid: CSIC.

Civale, G. (2008). Con secreto y disimulación: Inquisizione ed eresia nella Siviglia del secolo XVI. Nápoles: Edizioni Scientifiche Italiane.

Droz, E. (1960). «Note sur les impressions genevoises transportées par Hernández». Bibliothèque d'Humanisme et de Renaissance, 22, 119-132.

Fernández Serrano, F. (1969). Obispos auxiliares de Zaragoza en tiempos de los arzobispos de la Casa Real de Aragón (1460-1575). Zaragoza: CSIC.

García Pinilla, I. J. (2012). «Lectores y lectura clandestina en el grupo protestante sevillano del siglo XVI». En: Vega, Maria José y NaKLÁdalová, Iveta (eds.). Lectura y culpa en el siglo XVI: Reading and Guilt in the 16th Century. Barcelona: Universitat Autònoma de Barcelona, 45-62.

Gómez URIEL, M. (2001). Bibliotecas antigua y nueva de escritores aragoneses de Latassa. Pamplona: Prensas Universitarias de Zaragoza.

Guerrero, R. (1969). Catecismos españoles del siglo XVI: La obra catequética del Dr Constantino Ponce de la Fuente. Madrid: Instituto Superior de Pastoral.

Hazañas y La Rúa, J. (1909). Maese Rodrigo (1444-1509). Sevilla: Librería e Imp. de Izquierdo y Cía.

Huerga, A. (1990). «Procesos de la Inquisición a los herejes de Sevilla, 1557-1562». En: Peláez, M. J. (ed.). Historia de la Iglesia y de las instituciones eclesiásticas: Trabajos en homenaje a Ferrán Valls $i$ Taberner. Barcelona, 4107-4144.

KAHN, D. (2011). «Et ne sub specie pietatis impietas disseminetur...». L'Inquisition espagnole au temps de Charles Quint (1516-1556): des innovations structurelles à l'épreuve des nouvelles menaces. Tesis de doctorado mecanografiada. Montpellier: Université Montpellier 3.

Kinder, A. G. (1978). «Juan Morillo, catholic theologian at Trent. Calvinist elder in Frankfurt. Bibliothèque d'Humanisme et de Renaissance, 38, 345-350.

- (1986a). «Juan Pérez de Pineda (Pierius). «Un ministro calvinista español del Evangelio en el siglo XVI en Ginebra». Diálogo Ecuménico, 69, 31-64.

- (1986b). «Un grupo de protestantes del siglo XVI en Aragón desconocido hasta ahora». Diálogo Ecuménico, 70-71, 171-216.

- (1986c). «Dos cartas hasta ahora desconocidas de Juan Pérez de Pineda, protestante sevillano del siglo XVI». Archivo Hispalense, 210, 85-96.

LeCler, J. (1955). Histoire de la tolérance au siècle de la Réforme. París: Aubier.

LONGHurst, J. E. (1960). «Julián Hernández, protestant martyr». Bibliothèque d’Humanisme et de Renaissance, 22, 90-118.

López Muñoz, T. (2011). La Reforma en Sevilla. Sevilla: Eduforma Historia. 2 vol.

Martínez Millán, J. (2004). «Corrientes espirituales y facciones políticas en el servicio del Emperador Carlos V». En: Blockmans, W. P. y Mout, M. E. H. N. (eds.). The World of Emperor Charles V. Amsterdam, 97-126.

Pastore, S. (2010). Una herejía española: Conversos, alumbrados e Inquisición (14491559). Madrid: Marcial Pons.

Pollet, Jacques V. (1990). Julius Pflug (1499-1564) et la crise religieuse dans l'Allemagne $d u$ XVI $I^{e}$ siècle. Leiden: Brill. 
Redondo, A. (2001). «El doctor Egidio y la predicación evangelista en Sevilla durante los años 1535-1549». Carlos V. Europeísmo y universalidad. Madrid: Sociedad Estatal para la Conmemoración de los Centenarios de Felipe II y Carlos V, V, 577-598.

SeIDel MenchI, S. (1996). Erasme hérétique, Réforme et inquisition dans l'Italie du XVI ${ }^{e}$ siècle. Traducción del italiano. París: Seuil.

Tellechea Idígoras, J. I. (1963a). Fray Bartolomé Carranza. Documentos Históricos. Madrid: Real Academia de la Historia, II. 2.

- (1963b). «Españoles en Lovaina en 1551-1558. Primeras noticias sobre el bayanismo». Revista Española de Teología, 23, 21-45.

- (1967). «Una denuncia de los cardenales Contarini, Pole y Morone, por el cardenal Francisco de Mendoza». Revista Española de Teología, 27, 35-51.

Thомаs, W. (2001). La represión del protestantismo en España, 1517-1648. Lovaina: Leuven University Press.

Truman, R. W. (1984). «Felipe de la Torre and his Institución de un rey Christiano (Antwerp, 1556). The Protestant Connections of a Spanish Royal Chaplain». Bibliothèque d'Humanisme et Renaissance, 46, 83-93.

Truman, R. W. y Kinder, A. G. (1979). «The Pursuit of Spanish Heretics in the Low Countries: The Activities of Alonso del Canto, 1561-64». Journal of Ecclesiastical History, 30, 65-93.

Verzosa, Juan de (2006). Epístolas. Editado por E. del Pino González. Alcañiz. Madrid: Consejo Superior de Investigaciones Científicas. 